\title{
Impaired awareness of deficits and cognitive strategy use in occupational performance of persons with acquired brain injury (ABI)
}

Sabine van Erp and Esther Steultjens

Department of Occupational Therapy, Hogeschool Arnhem Nijmegen (HAN) University of Applied Science, Nijmegen, The Netherlands

Persons with acquired brain injury

Received 5 October 2019 Revised 2 January 2020 13 April 2020 9 July 2020 Accepted 16 July 2020

\begin{abstract}
Purpose - This study aims to explore the difference in cognitive strategy use during observed occupational performance between and within different levels of impaired awareness of deficits of individuals with acquired brain injury (ABI).

Design/methodology/approach - A cross-sectional study $(N=24)$ of individuals with ABI receiving rehabilitation and with the capacity to demonstrate goal-directed behaviour (Allen cognitive level screen score $=4.0)$ was undertaken. Cognitive strategy use during occupational performance of daily activities (measured with the perceive, recall, plan and perform [PRPP]) was evaluated between and within different awareness levels (awareness levels measured by the self-regulation skill interview). Statistical analyses, using independent $t$-test, Mann Whitney U test, ANOVA and Friedman test, were executed.

Findings - Significant differences were shown for both strengths and weaknesses in cognitive strategy use between emergent $(n=13)$ and anticipatory awareness $(n=11)$ groups on PRPP items "perceive", "sensing" and "mapping"; and "searches", "recall steps", "identify obstacles", "calibrates", "stops", "continues" and "persists". Within emergent awareness group, participants scored lowest related to "perceive", "plan", "sensing", "mapping", "programming" and "evaluating". Within anticipatory awareness group, participants scored lowest related to "plan", "programming" and "evaluating".

Practical implications - This study showed differences in cognitive strategy application during task performance in individuals with emergent or anticipatory awareness deficits that fit with theoretical expectations. It is recommended to make use of the PRPP assessment results (strengths and weaknesses in cognitive strategy application) to support the level of awareness determination. The PRPP assessment results and the level of awareness tailor the clinical reasoning process for personalised intervention planning and cognitive strategy training.
\end{abstract}

(C) Sabine van Erp and Esther Steultjens. Published in Irish Journal Occupational Therapy. Published by Emerald Publishing Limited. This article is published under the Creative Commons Attribution (CC BY 4.0) license. Anyone may reproduce, distribute, translate and create derivative works of this article (for both commercial and non-commercial purposes), subject to full attribution to the original publication and authors. The full terms of this license may be seen at http://creativecommons.org/ licences/by/4.0/legalcode

The authors would like to acknowledge all the participants that gave consent for using the data for research purposes. Also, all the occupational therapists and psychologists from the rehabilitation centers and multidisciplinary community centers for collecting the data for my research, specifically, Anne-Claire Schrijnemakers for the Dutch translation of the Self-Regulation Skill Interview and Karen Ethridge for her guidance during the research.

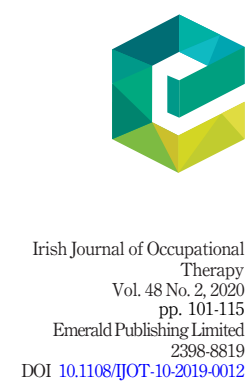


IJOT

48,2

102

Originality/value - Because impaired awareness has so much impact on the course and outcome of rehabilitation (Rotenberg-Shpigelman et al., 2014), in clinical practice, it is of paramount importance to be aware of the level of awareness of the client (Smeets et al., 2017) and the effect on occupational performance.

Keywords Acquired brain injury, Performance, Rehabilitation, Daily activities, Impaired awareness of deficits, Intellectual, Emergent, Anticipatory, PRPP

Paper type Research paper

\section{Introduction}

Acquired brain injury (ABI) is one of the major causes of disability and death worldwide. Annually, there are 160,000 new cases in The Netherlands (Hersenstichting, 2015). Impaired awareness of deficits refers to the reduced ability to appraise one's own strengths and weaknesses and to know the related implications for daily activities in the present, as well as in the future (Fleming et al., 1996; Prigatano and Schacter, 1991; Smeets et al., 2012). Noting impaired awareness of deficits is one of the cognitive deficits after ABI (Bach and David, 2006). The prevalence of individuals with impaired awareness of deficits ranges from $45 \%-$ $97 \%$ depending on the type and severity of the injury and time since injury (Hartman-Maeir et al., 2003; Freeland, 1996; Sherer et al., 1998). This is an important group of clients seen within rehabilitation; therefore, it is important to address awareness of deficits in rehabilitation.

Individuals with impaired awareness have the inability to set functional and realistic goals and are not able to recognise their need for assistance (Rotenberg-Shpigelman et al., 2014). They have the inability to engage in therapies, which may lead to difficulty in achieving and maintaining productive and independent living (Winkens et al., 2014). Other consequences of impaired awareness are decreased motivation to learn (Toglia and Kirk, 2000), long-term emotional dysfunctioning (Winkens et al., 2014), inhibition of selfsupporting lifestyle (e.g. disabled independence), no return to employment and reduced independent living status (Long et al., 2014). Clinicians believe impaired awareness is, besides cognition and motivation, one of the three major aspects that influences the individuals' learning ability (Boosman, 2015; Robertson and Schmitter-Edgecombe, 2015; Winkens et al., 2014). Thus, impaired awareness leads to impaired occupational performance, which is defined as:

the ability to perceive, desire, recall, plan and carry out roles, routines, tasks and sub-tasks for the purpose of self-maintenance, productivity, leisure and rest in response to demands of the internal and/or external environment (Ranka and Chapparo, 1997).

Therefore, it is of great importance to address this properly during rehabilitation.

To assess and treat the phenomenon of impaired awareness, first, it is important to understand the concepts of the theoretical frameworks that conceptualises the phenomenon of impaired awareness. Crosson et al., (1989) described three levels of impaired awareness in a hierarchical model. The first and lowest level of awareness is intellectual awareness, which means that the patient understands that a specific function is impaired compared to before the injury. The second level is emergent awareness, whereby the patient can recognise the impairment when it actually occurs in daily life. The last and highest level is anticipatory awareness, which refers to the ability to anticipate problems that will occur in future owing to the impairments (Crosson et al., 1989). This model has been criticised on its hierarchy. In response, Toglia and Kirk (2000) introduced a more interactional model, while Ownsworth et al., (2006) introduced a biopsychosocial framework. For all these frameworks, authors state that further research is needed (Crosson et al., 1989; Ownsworth et al., 2006; Toglia and 
Kirk, 2000). In spite of ongoing criticism, the model by Crosson et al., (1989) is frequently used in rehabilitation settings. Its purely descriptive construct offers a useful guideline for clinicians and provides direct implications for rehabilitation assessment and treatment (Fleming et al., 1996; Ownsworth et al., 2006; Smeets, 2015).

In addition, Winkens et al., (2014) argued that it is not easy to measure different aspects of self- awareness in a standardised way. They found that only $7.4 \%$ of clinicians used a standardised measure to assess self-awareness. Instruments used were limited to measuring awareness with respect to intellectual awareness (Rotenberg-Shpigelman et al., 2014; Winkens et al., 2014). Self-evaluation of the individuals functioning is compared to the actual score on a neuropsychological test (Hoofien et al., 2004). Typically, in clinical practice and in research, emergent awareness and anticipatory awareness are generally measured by comparing the self-ratings of the person's expected performance with the therapist's ratings after activity performance. Individuals with ABI rate their ability to perform better than their actual performance as rated by therapists (Abreu et al., 2001).

Bouwens (2009) found that daily life functioning of individuals with ABI could not be predicted by neuropsychological assessment only. Direct observation of the performance of daily activities is recommended as a complementary tool to neuropsychological assessment to measure both cognitive deficits and cognitive strategy use during daily performance to support intervention planning (Bouwens, 2009; Chapparo and Ranka, 2013).

Cognitive strategies can be defined as the use of cognition (the mind) to complete a task or solve a problem (Chaparro, 2014), which helps people function effectively and supports goal-directed behaviours (Harvey and Goudvis, 2007). The ability to choose, adapt and apply a strategy that is the most suitable for a specific situation is called cognitive strategy use. The success of cognitive strategy use depends on the quality of information processing which is needed for successful occupational performance (Chaparro, 2017). Occupational therapists are specialised in assessing functional performance and impairment of cognition.

The aim of this study was to explore the difference in cognitive strategy use during observed occupational performance between and within different awareness levels of individuals with $\mathrm{ABI}$.

\section{Materials and methods \\ Design}

This research was a quantitative, quasi-experimental and cross-sectional design. In this design, there were three participant groups, which were formed based upon their level of awareness (intellectual, emergent or anticipatory awareness). This design was used to explore relationships between different variables. The independent variable (IV), awareness, was identified but not manipulated and the relationship with the IV on the dependent variable (DV), performance of daily activity, was measured and analysed. The performance of a daily task was measured for every member of each group using the perceive, recall, plan and perform (PRPP) (Chapparo and Ranka, 2013). Data were collected between March and May 2016 from three rehabilitation centres and six multidisciplinary community health centres in The Netherlands.

\section{Procedure: inclusion participants}

The inclusion criteria for participation were:

- adults with $\mathrm{ABI}$ (regardless of type of $\mathrm{ABI}$ or date of onset) following an inpatient or outpatient rehabilitation programme; 
IJOT

48,2

104

- individuals without severe cognitive impairments and/or severe aphasia, respectively, based on an Allen cognitive levels screen (ACLS) score $\geq 4.0$ (Allen et al., 2007) and the clinical decision of the occupational therapist and/or the psychologist based on clinical expertise; and

- treating therapists were willing and able to engage in data collection.

The ethical committee of the University of Applied Science in Nijmegen approved the research on the 16 February 2016 with reference number ACPO 20.02/16.

\section{Procedure: data collection}

Before starting the data collection, the participants were informed by their own treating therapist, about the study using a participant's information sheet. After sufficient understanding of the study was verbally checked by the therapist, informed consent to use the clinical data for analyses purposes was given in writing by the participating individuals with ABI. The last step before including the individuals was administering the ACLS. In the first step of data collection, the two assessments, self-regulation skill interview (SRSI) and PRPP (Chapparo and Ranka, 2013), were administered in two separate therapy sessions. First, the SRSI was administered by a psychologist and, second, the PRPP was administered by an occupational therapist. To administer the PRPP, the occupational therapist and the participant chose together a meaningful task that was challenging enough (meaning a mastery score $\leq 80 \%$, reflecting the disability problem of the specific participant).

\section{Materials}

The ACLS differentiates between the lowest cognitive level 3.0 and the highest cognitive level 5.8 (of the cognitive disabilities model) based on the person's actual performance on an unfamiliar short task (Allen et al., 2007). From the level 4.0, the global cognition of the client is moderately impaired, but the client has the capacity to demonstrate goal-directed behaviour (Allen et al.,1992). High inter-rater reliability, test-retest reliability and a good construct validity have been found with psychiatric populations (Allen, 1991; Penny et al, 1995; Velligan et al., 1998) but not tested with individuals with ABI. In spite of lack of standardisation in an ABI cohort, in clinical practice, the ACLS is found to be a useful tool as described behaviours occur commonly in this group of patients (Steultjens et al., 2013; Urmston, 2010).

The SRSI measures all levels of awareness. The seven questions are scored on a ten-point Likert scale (Ownsworth et al., 2000). Good construct validity and inter-rater reliability of the SRSI have been identified (Ownsworth et al., 2000). According to T. Ownsworth, a cut-off score between emergent and anticipatory awareness is not specifically addressed in Questions 1 and 2 of the SRSI (personal communication, 24 May 2016). Therefore, the outcomes of the SRSI have been reviewed by the first researcher and a qualified neuropsychologist to differentiate between levels of impaired awareness.

The PRPP (Figure 1) measures cognitive strategy use during the performance of a freely chosen, meaningful daily activity (Nott et al, 2009). The PRPP assessment uses a two-stage analysis process. In Stage 1, errors in everyday task performance are identified, which generate an overall measure of mastery, stating the level of independency, for the specific activity. The chosen activity is procedurally analysed and divided in steps. The mastery of the activity is based on the number of mistakes the person makes during performance of the activity (directed by step). The level of mastery is displayed in percentage, $0 \%$ when the person is unable to perform the activity and $100 \%$ when the person can perform the activity without any problems. The activity is cognitively challenging enough if mastery level is below $80 \%$; the activity will give a clear picture of the problems in cognitive strategy use (Chapparo and Ranka, 2013). 


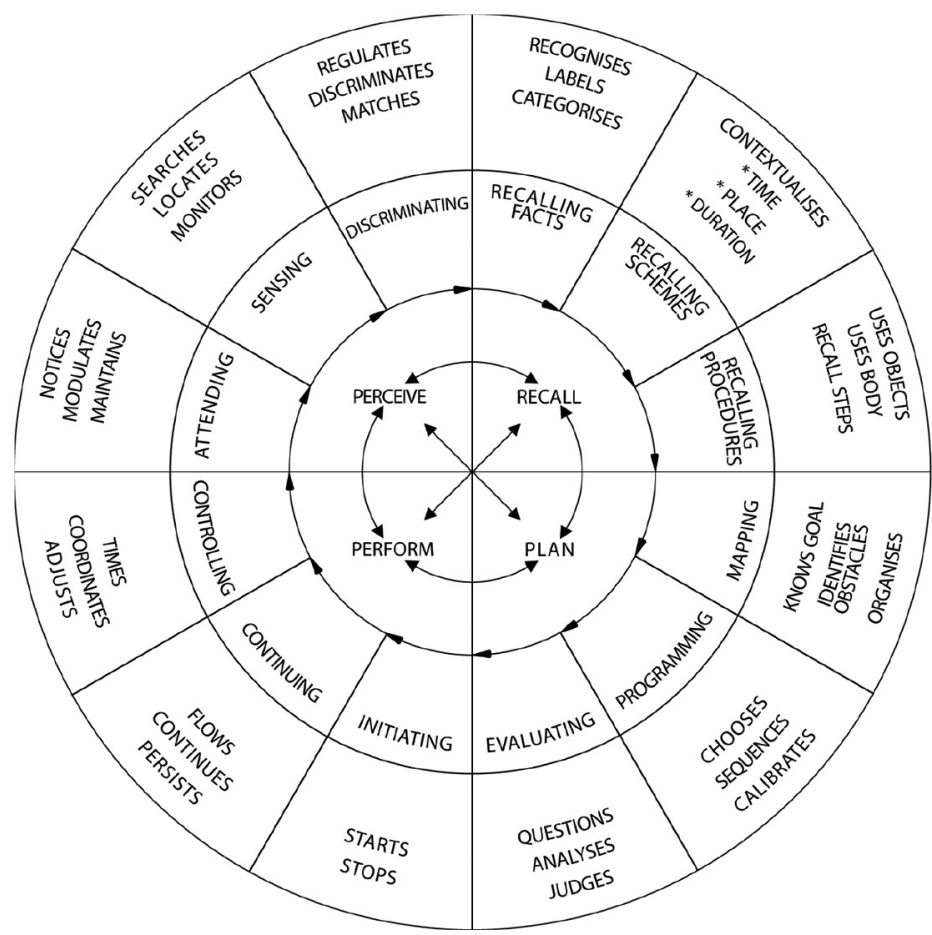

Persons with acquired brain injury

Figure 1. PRPP system of task analyses

Stage 2 of the PRPP explains how the profile of current information processing relates to this level of mastery and focusses on cognitive strategies required for task performance. A three-point rating scale is used to score the patient's performance on each descriptor as (3) effective for task performance, (2) questionable or (1) not effective. The summed score of Stage 2 for the whole PRPP ranges from 35 to 105, the summed score of each quadrant ranges from 9 to 27 and the summed score of each sub-quadrant ranges from 3 to 9 . Higher scores reflect more strengths in cognitive strategy application.

The PRPP has a moderate inter-rater reliability and good test reliability; it has been found to be a valid measure of cognitive strategy use for adults with brain injury and it demonstrates high validity on test items regarding information-processing strategies (Chapparo and Ranka, 2008; Nott et al., 2009; Nott and Chaparro, 2012).

\section{Analysis}

The data were analysed with respect to four aspects. The first three aspects were normally distributed and concerned interval data and included for:

- (Aspect 1) total summed score of the PRPP reflecting the whole profile of information-processing difficulties;

- (Aspect 2) four quadrant summed scores (e.g. "perceive”, "recall", "plan" and "perform"); and

- (Aspect 3) 12 sub-quadrant summed scores, such as "attending" and "discriminating". 
IJOT

48,2

106

The data for these three aspects was retrieved from aggregated rating scales (Harpe, 2015). In this study, sums of descriptor scores were used to obtain total scores, quadrant scores and sub-quadrant scores. The data was treated as an interval scale, according to the criteria provided by Harpe (2015). The data from the fourth aspect of analysis contained ordinal data (score of 1,2 or 3 ) for each of the 35 descriptor scores.

\section{Between groups comparison}

The two groups were compared on:

- Aspect 1: total score of the PRPP.

- Aspect 2: four quadrant scores.

- Aspect 3: 12 sub quadrant scores.

- Aspect 4: 35 descriptor scores.

To compare summed scores between two groups, an independent $t$-test, to fit the unpaired parametric interval data, was used for Aspects 1, 2 and 3. For Aspect 4, the Mann-Whitney U-test, for unpaired comparison of ordinal data between two groups, was used.

\section{Within groups comparison}

Within groups, ANOVA, for paired parametric multi-group comparisons, was used for analyses on PRPP quadrant (Aspect 2) and sub-quadrant level (Aspect 3) to test the differences in cognitive strategy application patterns within both groups separately on the 4 quadrants and 12 sub-quadrants. The Bonferroni correction was used to address the influence of these pairwise comparisons. To test the differences in performance within the group for the 35 descriptors (Aspect 4), the Friedman test, for comparison of three or more paired groups of ordinal data, was used with automatic Bonferroni correction. This test provides a Chi-square statistic.

\section{Results}

Three rehabilitation centres and six multi-disciplinary health centres participated and the study included 24 participants, 16 from rehabilitation centres (10 inpatients and 6

\begin{tabular}{|c|c|c|c|}
\hline & $\begin{array}{l}\text { Total group } \\
\qquad(N=24)\end{array}$ & $\begin{array}{c}\text { Emergent awareness } \\
\quad(N=13)\end{array}$ & $\begin{array}{c}\text { Anticipatory awareness } \\
\qquad(N=11)\end{array}$ \\
\hline $\begin{array}{l}\text { Age, } M(S D) \text { year } \\
\text { Gender, } M / F\end{array}$ & $\begin{array}{l}59(10.97) \\
14 / 10\end{array}$ & $\begin{array}{l}61(9.62) \\
8 / 5\end{array}$ & $\begin{array}{c}59(12.96) \\
6 / 5\end{array}$ \\
\hline $\begin{array}{l}\text { Type ABI } \\
\text { Stroke RH } \\
\text { Stroke LH } \\
\text { Contusio cerebri } \\
\text { Other* }\end{array}$ & $\begin{array}{l}8 \\
7 \\
1 \\
8\end{array}$ & $\begin{array}{l}3 \\
3 \\
1 \\
6\end{array}$ & $\begin{array}{c}5 \\
4 \\
- \\
2\end{array}$ \\
\hline $\begin{array}{l}\text { Time since onset } \\
M(S D) \text { months } \\
\text { ACLS } \\
M(S D)\end{array}$ & $\begin{array}{l}7.18(18.74) \\
4.97(0.59)\end{array}$ & $\begin{array}{c}10.15(25.87) \\
4.77(0.48)\end{array}$ & $\begin{array}{l}3.91(4.16) \\
5.17(0.66)\end{array}$ \\
\hline
\end{tabular}

Table 1.

Composition and characteristics of the groups

Notes: "Others = multiple stroke, stroke basal ganglia 


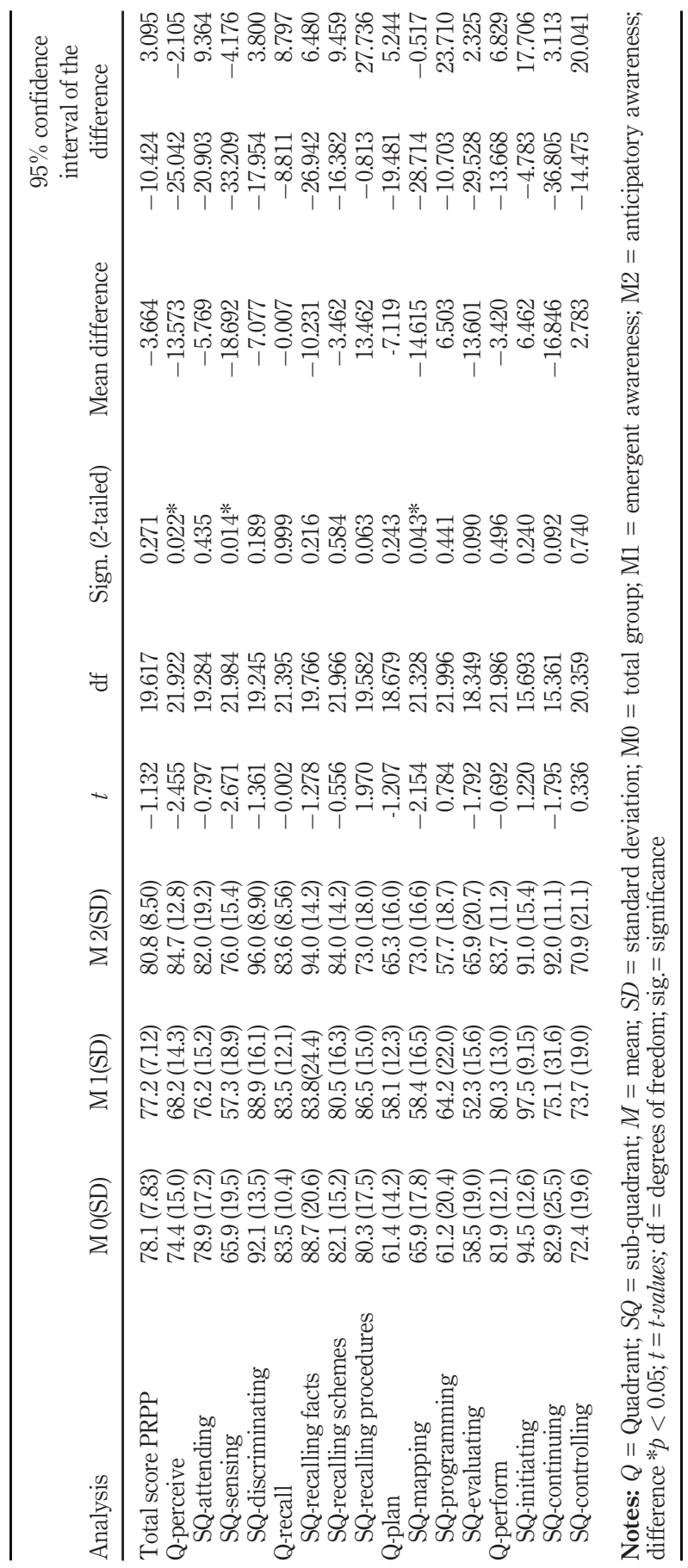

Persons with acquired brain injury

107

Table 2.

Descriptive and inferential statistics PRPP Stage 2, total PRPP, quadrants and sub-quadrants 
IJOT

48,2

108

outpatients) and 8 people from multidisciplinary health centres. Based on their SRSI, the participants were divided in two groups related to level of awareness: $(1=$ emergent awareness $[n=13]$ and $2=$ anticipatory awareness $[n=11])$. Table 1 shows the composition and the characteristics of the groups.

The collected data were analysed statistically for the emergent awareness group and the anticipatory awareness group. The intellectual awareness group was excluded because it contained only one participant. This participant is not mentioned in the results section. The PRPP data for Stage 2 was tested for normality, both groups' data showed a normal distribution (1: skewness of -1.001 [SE $=0.616]$, kurtosis of 1.853 [SE $=1.191]$ [no significance Shapiro Wilk test]; 2: skewness of 0.838 [SE $=0.616]$, kurtosis of 0.598 [SE = 1.279][no significance Shapiro Wilk test]).

The results of the between and within comparison of the performance will be presented further on the four aspects. Performance described as "higher than" implicates that this aspect is less difficult than other aspects. Performance described as "less than" implicates it is more difficult than other aspects.

\section{Between groups comparison}

For the first analysis (total summed score of the PRPP), there were no significant differences between groups (Table 2). For the second analysis (quadrant summed scores), the descriptive data shows that both groups had the lowest score on the "plan" quadrant and its sub-quadrants "programming" and "evaluating" and the highest score on the quadrant "recall". The interferential results show that the emergent awareness group scored significantly lower than the anticipatory awareness group, on the quadrant "perceive" $(\mathrm{d}=1.04, p=0.022, p<0.05)$. For the third analysis (sub-quadrants summed scores), the performance of the emergent awareness group was significantly less, compared to the anticipatory awareness group, on the sub-quadrants "sensing" and "mapping" ( $p=0.014, p=0.043, p<0.05$ ) (Table 2). For the fourth analysis (descriptor scores), the emergent awareness group performed significantly better on the cognitive strategy application of "recall steps", "calibrates" and "stops" $(p=0.024, p=0.007, p=$ $0.049, p<0.05$ ) and performed significantly lower on the cognitive strategy application of "searches", "identify obstacles", "continues" and "persists" $(p=0.047, p=0.009, p=$ $0.024, p=0.024, p<0.05)$.

\section{Within groups comparison}

The results of the within groups ANOVA, show a significant difference in performance within both awareness groups on quadrants and sub-quadrants levels (Table 3). The pairwise comparisons show that the performance of the emergent awareness group was significantly higher on "recall" $(p=0.008, p<0.05)$ and "perform" $(p=0.048, p<0.05)$ than

Table 3.

Within groups ANOVA: PRPP quadrants and subquadrants

\begin{tabular}{llccccc}
\hline \multirow{2}{*}{ PRPP } & Level of awareness & $\begin{array}{c}\text { Type III sum } \\
\text { of squares }\end{array}$ & df & Mean square & F & Sig. \\
\hline Quadrants & Emergent & 5297.538 & 2.446 & 2166.061 & 12.382 & $0.000^{*}$ \\
& Anticipatory & 2619.523 & 2.313 & 1132.360 & 7.980 & $0.002^{*}$ \\
Sub-quadrants & Emergent & 28054.154 & 5.686 & 4933.883 & 7.506 & $0.000^{*}$ \\
& Anticipatory & 17892.811 & 5.161 & 3467.155 & 7.111 & $0.000^{*}$
\end{tabular}

Notes: ${ }^{*} p<0.05 ; \mathrm{df}=$ degrees of freedom; $\mathrm{F}=\mathrm{F}$ value; Sig. $=$ significance 


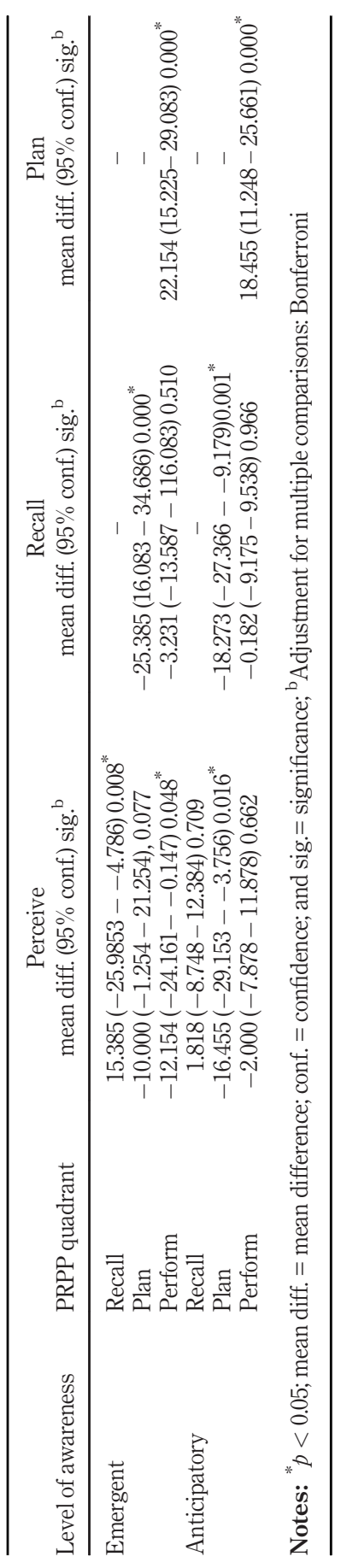

Persons with acquired brain injury

109

Table 4.

Within groups analyses: pairwise comparison quadrants 
on "perceive" and "plan". The performance of the anticipatory awareness group was significantly higher on "perceive", "recall" and "perform" than on "plan" $(p=0.016, p=$ $0.001, p<0.05$, respectively) (Table 4).

The performance of the sub-quadrants within the emergent awareness group was significantly higher on the sub-quadrant "attending" than "sensing" and "evaluating" $(p=$ $0.026, p=0.018, p<0.05)$, higher on "discriminating" than "mapping" and "evaluating" $(p=$ $0.031, p=0.015, p<0.05)$ and higher on "initiating" than "mapping", "programming" and "evaluating" ( $p=0.000, p=0.004, p=0.000, p<0.05)$. The performance was significantly lower on "sensing" than "discriminating", "recalling procedures" and "initiating" $(p=0.021$, $p=0.026, p=0.003, p<0.05)$ and lower on "evaluating" than "recalling schemes" and "recalling procedures" ( $p=0.012, p=0.001, p<0.05$ ) (results not presented in table).

The performance of the sub-quadrants within the anticipatory awareness group was significantly higher (less difficult) on "discriminating" than on "programming" and "evaluating" ( $p=0.006, p=0.043, p<0.05)$. The performance was significantly lower on the sub-quadrants "programming" than "recalling facts" and "continuing" $(p=0.011, p=0.002$, $p<0.05)$ (results not presented in table).

For both emergent awareness and anticipatory awareness groups, the performance on the different descriptors is statistically significant $\left[\chi^{2}(2)=180,065, p<0.05, \chi^{2}(2)=103,872\right.$, $p<0.05]$ (results not presented in table).

\section{Discussion}

The aim of this study was to explore the differences in cognitive strategy use during observed occupational performance between and within different awareness levels of individuals with ABI. The analysis of the PRPP observation scores showed both similarities and differences. In general, similarities in cognitive strategy application were found. All participants encountered difficulties during task performance because they all choose an activity that was challenging enough (the $80 \%$ rule). Both groups had the lowest score of the quadrant planning and its sub-quadrants programming and evaluating. As shown for both groups in the within groups comparison, the most difficult part in information processing during the performance of a daily activity were the cognitive strategies that belonged to the quadrant "plan". The hierarchical order of the PRPP descriptors, described in previous research, is in line with this finding; the descriptors of the "plan quadrant" are in general cognitively harder to execute compared to the descriptors of the other three quadrants (Nott and Chaparro, 2012). This hierarchy is congruent with the theory of human cognition. This theory organises human cognition into a hierarchy of basic and complex processes. The basic processes are sensory perception, attention and memory mechanisms. These basic processes are necessary for more complex processes, such as planning and problem-solving (Constantinidou and Thomas, 2010).

Another similarity, shown from both the in between and the within comparison, is that both groups of awareness performed best on the quadrant "recall". This is in line with the expectation, based on previous knowledge, because this quadrant reflects recalling knowledge about one self and the environment from the past to guide performance in the presence (Chapparo and Ranka, 2013) and fits with the freely chosen meaningful activities in this study. This metacognitive knowledge available prior to the activity is also described as intellectual awareness (Toglia and Kirk, 2000), which is the foundation for the next levels of awareness (Crosson et al., 1989; Ownsworth et al., 2000). Therefore, the outcome on the quadrant "recall" in our study confirms that both groups had sufficient intellectual awareness abilities, which is in line with the hierarchical model of Crosson et al., (1989). 
The important overall difference, based on both the in between and the within comparisons, was that participants with anticipatory awareness significantly performed better than participants with emergent awareness on the quadrant "perceive", the subquadrants "sensing" and "mapping" and the descriptors "searches", "identify obstacles", "continues" and "persists". This is in line with theoretical expectations, as most of the activities in our study were performed in an unfamiliar environment to the participant. Awareness is task dependent, determined by the type of the activity, the familiarity and the difficulty (Bandura, 1997; Toglia and Kirk, 2000). People with emergent awareness are therefore expected to show more difficulties in systematically and actively seeking sensory information, when performing a daily activity in an unfamiliar environment. They are not able to fully anticipate a problem when it occurs (Crosson et al., 1989). Moreover, those with emergent awareness are not able to realise in advance that a particular impairment can cause a certain problem in the future, which is needed to identify obstacles (Crosson et al., 1989). Last, a lower awareness seems intuitively to be associated with low motivation to persist and complete the activity (Smeets, 2015; Toglia and Kirk, 2000), which is part of the behaviour defined in the PRPP descriptors "continues" and "persists" (Chapparo et al., 2017).

The participants with emergent awareness significantly performed better on the descriptors "recall steps", "calibrates" and "stops" compared to the participants with anticipatory awareness. This might be explained by the fact that the group of anticipatory awareness mainly performed new activities to achieve the right level of difficulty in this study. When an activity is new, steps cannot be recalled from their memory (Chapparo et al., 2017). Another explanation can be that participants with anticipatory awareness probably stopped more regularly during task performance compared to participants with emergent awareness. When an obstacle was identified, they had to look for extra information and think of a suitable solution for reaching the activities goal executing cognitive strategies needed for problem-solving. This fits with the found results of the within comparison of both groups in this study.

In the study by Toglia and Kirk (2000), problems that contribute to deficits in selfawareness are subdivided. For example, problems in self- knowledge such as false judgement or problems in performance such as not initiating self-checking (Toglia and Kirk, 2000). The problems that Toglia and Kirk (2000) describe generally correspond to the actual behaviour that was observed during performance of daily activities in this study. For example, false judgements correspond with judges observed in the PRPP.

\section{Strengths and limitations}

An important strength of this study is that the actual performance of daily activity is observed to describe the effect of impaired awareness levels on the functioning of individuals with ABI. This is congruent with the findings of Bouwens (2009) who found that the functioning of individuals with ABI in daily life could not be predicted based on neuropsychological test results alone. Direct observation of daily activities was recommended as a complementary tool so that both cognitive data and data of daily performance were used in assessing individuals with ABI (Bouwens, 2009).

The sample size of 24 is small and might be a limitation of this research. Other research on this topic showed a sample size of 18 (Nott and Chaparro, 2012) and 36 (Rotenberg-Shpigelman et al., 2014). In spite of the small sample, significant differences were found between the performance of people with emergent and anticipatory awareness and within each impaired awareness level. Rash analysis may be considered 
in future research, because it can be used in small samples with sufficient statistical power (Bond and Fox, 2001).

Another limitation is that the group of intellectual awareness was not part of the comparison. This could be because of using the ACLS score of 4.0 as a cut-off for inclusion of participants possibly excluding individuals without the capacity to demonstrate goaldirected behaviour, which might be related to the level of intellectual awareness. As evidence of the validity of the ACLS for use in ABI is still lacking (Steultjens et al., 2013) and because there was one participant included with intellectual awareness in the original sample, we are not sure whether this was the case. In future research, this aspect should be addressed more in-depth to include a larger group of individuals with intellectual awareness.

The last limitation was the use of the SRSI to divide the participants in different awareness levels. First, the SRSI was not validated in Dutch; a translation used in daily practice was also used in this research. Moreover, the developer of the SRSI argued that a cut-off score between emergent and anticipatory awareness is not specifically addressed in the SRSI. Therefore, the outcomes of the SRSI have been reviewed by the first researcher and a qualified neuropsychologist to differentiate between levels of impaired awareness. Independently, they interpreted the wordings of the person in combination with the scores. Based on the theory of Crosson et al., (1989) they divided the participants into groups: impaired intellectual and emergent or anticipatory awareness. Consensus was reached by discussion when differences in interpretation occurred.

In future research it is expected that, with a larger sample size, more differences in performance might be revealed between and within the different levels of awareness. This can both enlarge the tools for the therapists in treatment planning as can add theoretical in-depth knowledge regarding awareness and its related behaviours.

Another important aspect for future research is that awareness is dependent of the activity performed and can be evident in one activity and not in the other, e.g. when not observing a challenging enough activity. To reach the highest degree of awareness, it is important to be able to understand the implications of problems across different activities more in-depth. The level of awareness influences the course and the outcome of the rehabilitation; thus, the higher the level, the better the outcome of the rehabilitation (Boosman et al., 2013; Boosman, 2015). The above confirms the criticism on the model of Crosson et al., (1989). Therefore, it is recommended to analyse all the theories and models about awareness to ground an up-to-date overall theory of awareness.

\section{Clinical implications}

Because impaired awareness has so much impact on the course and outcome of rehabilitation (Rotenberg-Shpigelman et al., 2014), in clinical practice, it is of paramount importance to be aware of the level of awareness of the client (Smeets et al., 2017) and the effect on occupational performance. This study showed differences in cognitive strategy application during task performance in individuals with emergent or anticipatory awareness deficits that fit with theoretical expectations. It is recommended to make use of the PRPP assessment results (strengths and weaknesses in cognitive strategy application) to support the level of awareness determination. The PRPP assessment results and the level of awareness tailor the clinical reasoning process for personalised intervention planning and cognitive strategy training. 


\section{References}

Abreu, B.C., Seale, G., Scheibel, R.S., Huddleston, N., Zhang, L. and Ottenbacher, K.J. (2001), "Levels of self-awareness after acute brain injury: how patients' and rehabilitation specialists' perceptions compare”, Arch Phys Med Rehabilitation, Vol. 82.

Allen, C.K. (1991), "Cognitive disability and reimbursement for rehabilitation and psychiatry", Journal of Insurance Medicine, Vol. 23 No. 4.

Allen, C.K., Earhart, C.A. and Blue, T. (1992), Occupational Therapy Treatment Goals for the Physically and Cognitively Disabled, American Occupational Therapy Association, Bethesda, MD.

Allen, C.K., Austin, S.L., David, S.K., Earhart, C.A., McCraith, D.B. and Riska-Williams, L. (2007), Manual for the Allen Cognitive Level Screen-5 (ACLS-5) and Large Allen Cognitive Level Screen (LACLS-5), Camarillo, CA-ACLS and LACLS Committee.

Bach, L.J. and David, A.S. (2006), "Self-awareness after acquired and traumatic brain injury", Neuropsychological Rehabilitation, Vol. 16 No. 4, pp. 397-414.

Bandura, A. (1997), Self-Efficacy: The Exercise of Control, W.H. Freeman and Company, New York, NY.

Bond, T.G. and Fox, C.M. (2001), Applying the Rasch Model, Lawrence Erlbaum, Mahwah, NJ.

Boosman, H. (2015), "Learning after acquired brain injury: learning the hard way", Brain Center Rudolf Magnus,

Boosman, H., Visser-Meily, J.M.A., Winkens, I. and Van Heugten, C.M. (2013), “Clinicians' view on learning in brain injury rehabilitation”, Brain Injury, Vol. 27 No. 6, pp. 685-688.

Bouwens, S.F.M. (2009), Ecological Aspects of Cognitive Assessment, Neuropsych Publishers Department of Psychiatry and Neuropsychology Maastricht University.

Chaparro, C. (2014), "Introduction to stage two analysis", in Chaparro C. and J. Ranka. (Eds),The PRPP System of Task Analysis: User's Training Manual: Research Revised Edition. Occupational Performance Network: Discipline of Occupational Therapy, The University of Sydney, Sydney, Australia.

Chaparro, C. (2017), "Perceive, recall, plan and perform (PRPP): occupation- centred task analysis and intervention", in S. Rodger and Kennedy-Behr, A. (Eds), Occupation-Centred Practice with Children: A Particular Guide for Occupational Therapists, John Wiley and Sons, pp. 189-208.

Chapparo, C. and Ranka, J. (2008), “The PRPP system of task analysis: User's training manual”.

Chapparo, C. and Ranka, J. (2013), “The PRPP system of task analysis: User's training manual”.

Chapparo, C., Ranka, J. and Nott, M. (2017), "The occupational performance model (Australia): a description of constructs, structure and propositions", in M. Curtin, M. Egan and J. Adams (Eds), Occupational Therapy for People Experiences Illness, Injury or Impairment, (7th ed., 134-147). Edinburgh: Elsevier.

Constantinidou, F. and Thomas, R. (2010), "Principles of cognitive rehabilitation in TBI: an integrative neuroscience approach”, in: Ashley M., (Ed.), Traumatic Brain Injury: Rehabilitation, Treatment, and Case Management, 3rd ed. CRC Press, Boca Raton, FL: Taylor and Francis. pp 549-582.

Crosson, B., Barco, P.P., Velozo, C.A., et al., (1989), "Awareness and compensation in post-acute head injury rehabilitation”, Journal of Head Trauma Rehabilitation, Vol. 4 No. 3, pp. 46-54.

Fleming, J., Strong, J. and Ashton, R. (1996), "Self-awareness of deficits in adults with traumatic brain injury: How best to measure?”, Brain Injury, Vol. 19 No. 1, pp. 1-16.

Freeland, J. (1996), "Awareness of deficits: a complex interplay of neurological, personality, social and rehabilitation factors”, Magazine, Vol. 4, pp. 32-34.

Harpe, S.E. (2015), "How to analyze Likert and other rating scale data", Currents in Pharmacy Teaching and Learning, Vol. 7 No. 6, pp. 836-850.

Hartman-Maeir, A., Soroker, N., Oman, S.D. and Katz, N. (2003), "Awareness of disabilities in stroke rehabilitation: a clinical trial”, Disability and Rehabilitation, Vol. 25 No. 1, pp. 35-44. 

and Engagement, 2nd edn. Stenhouse Publishers, Portland, ME.

Hersenstichting (2015), "Cijfers over patienten", available at: www.hersenstichting.nl/alles-overhersenen/hersenaandoeningen/cijfers-over-patienten (accessed 30 Oktober 2015).

Hoofien, D., Gilboa, A., Vakil, E. and Barak, O. (2004), "Unawareness of cognitive deficits and daily functioning among persons with traumatic brain injury", Journal of Clinical and Experimental Neuropsychology, Vol. 26 No. 2, pp. 278-290.

Long, K., Rager, B. and Adams, G. (2014), "Deficit awareness and cognitive performance in individuals with acquired brain injury", NeuroRehabilitation, Vol. 34 No. 1, pp. 45-53.

Nott, M. and Chaparro, C. (2012), "Exploring the validity of the perceive, recall, plan and perform system of task analysis: cognitive strategy use in adults with brain injury", British Journal of Occupational Therapy, Vol. 75 No. 6, pp. 256-263.

Nott, M., Chaparro, C. and Heard, R. (2009), "Reliability of the perceive, recall, plan and perform system of task analysis: a criterion-referenced assessment”, Australian Occupational Therapy Journal, Vol. 56 No. 5, pp. 307-314.

Ownsworth, T., Clare, L. and Morris, R. (2006), "An integrated biopsychosocial approach to understanding awareness deficits in Alzheimer disease and brain injury", Neuropsychological Rehabilitation, Vol. 16 No. 4, pp. 415-483.

Ownsworth, T.L., McFarland, K. and McD. Young, R. (2000), "Development and standardization of the self-regulation skills interview (SRSI): a new clinical assessment tool for acquired brain injury", The Clinical Neuropsychologist, Vol. 14 No. 1, pp. 76-92.

Penny, N.H., Mueser, K.T. and North, C.T. (1995), "The Allen cognitive level test social competence in adult psychiatric patients", American Journal of Occupational Therapy, Vol. 49 No. 5, pp. 420-427.

Prigatano, G.P. and Schacter, D.L. (1991), "Online awareness of functional tasks following ABI: the effect of task experience and associations with underlying mechanisms", in Prigitano, G.P., Schacter, D.L. (Eds), Awareness of Deficits after Brain Injury: Clinical and Theoretical Issues, Oxford University Press, Inc, New York, NY City. pp. 3-16.

Ranka, J. and Chapparo, C. (1997), "Definition of terms", in Chapparo C. and Ranka J. (Eds), Occupational Performance Model (Australia): Monograph 1, (pp. 58-60). Occupational performance Network: Sydney, available at: www.occupationalperformance.com/definitions (accessed on 09-December-2018).

Robertson, K. and Schmitter-Edgecombe, M. (2015), "Self-awareness and traumatic brain injury outcome", Brain Injury, Vol. 29 Nos 7/8, pp. 848-858.

Rotenberg-Shpigelman, S., Rosen-Shilo, L. and Maeir, A. (2014), "Online awareness of functional tasks following ABI: the effect of task experience and associations with underlying mechanisms", NeuroRehabilitation, Vol. 35 No. 1, pp. 47-56.

Sherer, M., Bergloff, P., Levin, E., High, W.M., Jr, Oden, K.E. and Nick, T.G. (1998), "Impaired awareness and employment outcome after traumatic brain injury", The Journal of Head Trauma Rehabilitation, Vol. 13 No. 5, pp. 52-61.

Smeets, S.M.J. (2015), Insights into Insight: Studies on Awareness of Deficits after Acquired Brain Injury, School for mental health and neuroscience, Maastricht.

Smeets, S.M.J., Ponds, R.W.H.M., Verhey, F.R. and Van Heugten, C.M. (2012), "Psychometric properties and feasibility of instruments used to assess awareness of deficits after acquired brain injury: a systematic review", Journal of Head Trauma Rehabilitation, Vol. 27 No. 6, pp. 433-442.

Smeets, S.M., Vink, M., Ponds, R.W., Winkens, I. and van Heugten, C.M. (2017), "Changes in impaired self-awareness after acquired brain injury in patients following intensive neuropsychological rehabilitation", Neuropsychological Rehabilitation, Vol. 27 No. 1, pp. 116-132. 
Steultjens, E.M.J., Cup, E.H.C., Zajec, J. and Van Hees, S. (2013), Ergotherapierichtlijn CVA. Nijmegen/ Utrecht, Hogeschool van Arnhem en Nijmegen/Ergotherapie Nederland.

Toglia, J. and Kirk, U. (2000), "Understanding awareness of deficits following brain injury", NeuroRehabilitation, Vol. 15 No. 1, pp. 57-70.

Persons with acquired brain injury

Urmston, M. (2010), "De allen cognitive level screening (ACLS): gestandaardiseerd, betrouwbaar en valide", Nederlands Tijdschrift Voor Ergotherapie, Vol. 3 No. 2, pp. 18-19.

Velligan, D.I., Bow-Thomas, C.C., Mahurin, R., Miller, A., Dassori, A. and Erdely, F. (1998), "Concurrent and predictive validity of the allen cognitive levels assessment", Psychiatry Research, Vol. 80 No. 3, pp. 287-298.

Winkens, I., Van Heugten, C., Visser-Meily, J.M.A., Boosman, H., Caplan, B. and Bogner, J. (2014), "Impaired Self-Awareness after acquired brain injury: clinicians' ratings on its assessment and importance for rehabilitation", Journal of Head Trauma Rehabilitation, Vol. 29 No. 2, pp. 153-156.

\section{Corresponding author}

Sabine van Erp can be contacted at: sabine.vanerp@han.nl

For instructions on how to order reprints of this article, please visit our website: 